\begin{tabular}{c} 
Volume and Issues Obtainable at Center for Sustainability Research and Consultancy \\
Sustainable Business and Society in Emerging Economies \\
ISSN: 2708-2504 ISSN (E) 2708-2172 \\
Volume 1: No. 1, June 2019 \\
CSRᄃ \\
Journal homepage: $\underline{\text { www.publishing.globalcsrc.org/sbsee }}$ \\
\hline
\end{tabular}

\title{
Consumers' Attitude towards Use and Adoption of Online Shopping in Bahawalpur, Pakistan
}

\author{
${ }^{1}$ Muhammad Zeeshan Muneer
}

${ }^{1}$ The Islamia University of Bahawalpur Pakistan, zeesidhu@gmail.com

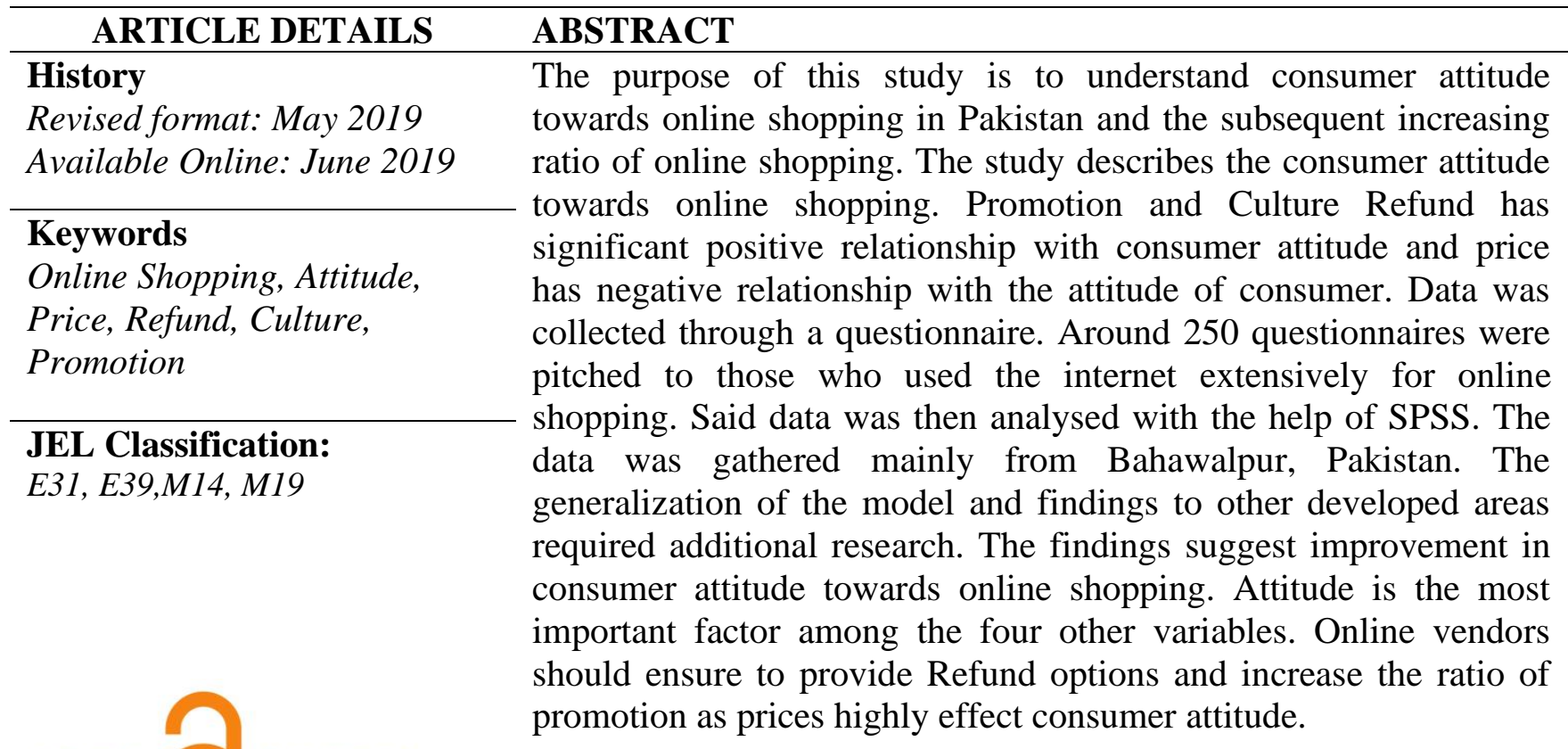

(C) 2019 The authors, under a Creative Commons AttributionNonCommercial 4.0

Corresponding author's email address: zeesidhu@ gmail.com

Recommended citation: Muneer, M. Z., (2019). Consumers' Attitude Towards Use and Adoption of Online Shopping in Bahawalpur, Pakistan. Sustainable Business and Society in Emerging Economies, 1(1), 1-14

DOI: $10.26710 /$ sbsee.v1i1.997

\section{Introduction}

Internet is one of the several channels of medium for selling and buying goods and services online. Online shopping means to place the order to buy the goods or services and the consumer can receive it while staying home. Consumers can use their credit cards and gain awareness about product features from different websites. Now-a-days it is becoming more and more convenient for the masses. Online shopping can be done through diverse sources like OLX, amazon, and daraz.pk by visiting the websites of different brands. Online shopping is a time saving process because people are too busy with their schedules which doesn't leave them with enough time to go visit the stores and peruse through shelves. Many people are satisfied and feel comfortable with online shopping because they are psychologically satisfied by using the online products, by their quality as well as by their pricing.

Every type of product or accessory can be purchased online these days like, electronics, transportation booking, stationery, food items, clothing etc. Even selling of products is done on online websites. E-trail 
is beneficent for both seller and buyer by reducing space and time hurdles. For buyers, e-trail provides platform of buying with far above the ground information and easiness of buying and the main thing is online shopping provides relief to the customer like there's no parking tickets or crowds to worry about. For seller, E-trail provides high interactive and accessible display place. Online shopping is changing the trend of spending. Its biggest advantage is that we can check the feedbacks or rating given by the customers who have already consumed those products and seeing good ratings can bring about psychological satisfaction. No doubt, the trend of online shopping is increasing day by day in Pakistan. Online shopping in sectors such as garments, mobile accessories and business-to-business transactions are growing in Pakistan. While online shopping is not at peak level in Pakistan, its growth rate is increasing steadily because of increase in day by day internet usage in Pakistan. The ratio of internet users in Pakistan in 2017 has exhibited exponential boom traits during the last few years - with US\$30 million being spent on line purchases presently - depict an extraordinarily advantageous photo for the future and the dimensions of Pakistan's e-trade market is predicted to reach over US\$800 million by means of 2018 (Ahmed, 2015). The total population of Pakistan is almost 200 million and internet user in Pakistan is 35.1 million on the other hand active social media user is 31 million, the numbers of smart phone users in Pakistan are 40 million, and the number of people who accessed social media from their smart phones is 28 million. The total value of e-commerce is estimated to cross the 10 billion mark by 2020. (Aurora)

E-commerce can be considered one of the most progressive and flashy businesses in the entire world. Rather it may be given the name of an abstract industry which is not only paying to an individual but increasing the revenue of states as well as countries also. According to a keen survey, the biggest countries (also known as super powers) whether economically, socially, in force or technologically and enhancing their revenue day by day with the help of ecommerce, or in simple words, online shopping.

The root reason of online shopping is to save time especially for those who are too busy in their social and practical life. The reason of this study is to examine the potential purchase behaviour of online shoppers in Pakistan with a purpose to gain insights into their attitudes, alternatives, decision-making body paintings, and lifestyles patterns. The target population examined for this consisted of the city consumers who're educated and belong to the top of the food chain and have socio-economic training. Within online purchasing, two primary classes will be set up, particularly "Electronics" and "garb."

Online shopping trend is rising in Asia rapidly but lot of problems were found in the way of its growing like price, promotion, refunds, trust and cultural factors. Amazon, eBay and OLX, along with many other companies have launched their services and products and get good response but it's not as satisfactory as in Asian countries like China, Pakistan, India and Japan. One of the major problem in online shopping in Asian countries like India, Pakistan, Sri Lanka, Malaysia, Iran, Turkey and Bangladesh is the literacy rate. The literacy rate is lower than we are thinking and if the right kind of education and awareness is provided, then you can see the positive signs in online shopping.

The biggest problem in online shopping is lack of trust. Most of the companies engage in fraudulent behaviours and the items are not the same as are shown on display. This practice not only breaks the customers trust but also damages the image of same well known reliable online firms which deters many from shopping online (rahim, 2012). Though same global level companies have provided quality, quantity and originality for the customers at the same level as Amazon, eBay and OLX etc. Promotions and discount play an important role in online shopping. Because $60 \%$ to $80 \%$ of the consumers wait for their trusted brands to put out seasonal sales, limited time period discounts and special offers for the holiday season. $59 \%$ of consumers search for promo code before buying online product while $22 \%$ of consumers purchase product from their preferred brands only when on sale or with coupon. (Shamout, The Impact of Promotional Tools on Consumer Buying Behavior in Retail Market, 2016)

The improvement of E-trade is tested by a few components related both market interest sides. Despite the fact that organizations broadly created value-based sites for their customer's satisfaction, but most of the 
online sites not fulfil the requirements of the consumers (Kooli). Online retail market provided a special services for their customers and introduce lot of a new products of relief on a daily basis like provide special product of daily base discount and consumers are more attract though the product. Online retail market introduce a separated market for all the products where you can easily find your product and save your time or expenses. The most effective advantage of online shopping is deals like buy get one get one free, coupons, discount. Most of the people don't prefer online shopping due to the security reasons and trust issues but when they watch different discount offers they are swayed into making a purchase because it's easy and on a less price as compared with offline market. (Shamout, The Impact of Promotional Tools on Consumer Buying Behavior in Retail Market, 2016)

The purchasing power and purchasing decision scene has changed all over the world since online shopping is directly affected by the consumers. Because in the 21 st century you can't sale your product without advertising. When a marketer make their product, they always choose a channel for promoting or advertising their product. In today's world you must be promote your product through online or sell it online because you can easily deliver your message to the audience. For an effective growth marketers must introduce different discounts and offers to their customers from time to time to attract them and build with their long term relationships. The main purpose of online shopping and advertising it online, is the ease of access. It's a speedy, effective and time saving process among other had increased the usage of online shopping to end the user. (Folarin, 2016)

As per marketing research on internet shopping in different nations, it was found that internet shopping in Philippines had been done by $62 \%$ of Filipino's web clients while $61 \%$ of Indonesian web clients shop on the web, $58 \%$ of Thailand and Vietnamese web clients utilize web based shopping, in any case, contrasted with these creating nations, web based shopping had been done in Malaysia by just $47 \%$ of Malaysian Internet clients. This level of internet shopping in Malaysia is generally low, along these lines it realized the motivation behind this examination which is to distinguish and look at the impact of seen hazard on shopping goal in Malaysia, explicitly in Malaysia's attire industry. (Folarin, 2016)

In different countries different consumers have different concern while purchasing any product online. The main advantage of online shopping is easily accessible and saves time but the disadvantage is facing security and privacy issues. Most of the developed countries decrease the security concern but lot of the developing countries like Pakistan and India still struggle with them. It's not a just a matter of concern for consumers, but also for all the online shopping companies who fear data leaks and tampering of sensitive data (Abrar, 2017).

It's a fact that web shopping has increased worldwide but, some online customers are still more partial towards offline shopping. They get information like price, specification or discount offers then they visit offline stores and purchase its online. (Shi, 2016) Buyers carefully buy online as a result of such obstructions as online dangers or security issues. Many researchers claim that risk is a main concern while any person is purchasing online. If any company or an organization satisfied their customers about their privacy or security they can easily survive in today's market and increase their sales very effectively (Sims, 2012).

China and UK are two developed countries, but when you compare these two nations, China's economy is three times bigger compared to England. But when you check out the ratio of internet users or online shopping users England's ratio is much higher than China's. There are a few motivations to choose the UK and China for correlation: right off the bat, they have altogether different social foundations, China, with its Asian culture, has conventional conviction and qualities which differ from those in a Western nation. For instance, the UK has a great broadband framework, 74\% of UK family used the broadband web associations, and $82 \%$ of the populations are internet users. In China the quantity of individuals utilizing broadband was 364 million. At last, Internet clients are keen on web based shopping in both nations. 51.07\% of the grown up population of UK had occupied with the web shopping, as compare with 
China they have just 26\% Chinese internet users shopping online. Out of these two developed nations UK internet client of online shopping ratio is much higher than China because China is a typical Asian country and UK is a developed western country. In UK online shopping users ratio increased due to the trust factor, because most of the UK Companies provided better security or privacy to their customers. Due to the better security and privacy UK online shopping ratio is increased day by day as compare with China. (Julian, 2012)

The quantity of internet consumers is expanding, especially in western and Asian nations, be that as it may, analysts have not given adequate consideration to why, how and at the point when purchasers utilize the Internet for their shopping, or why they don't pick on the web shopping. Online customers and offline customers may buy a few items on the web but not others. We must suss out the reasons for why people don't shop online or why some people just search on web about product specification. After search specification they don't buy it online (Sims, 2012).

In main concern of shopping online is some factors they have effect directly like trust, refund, culture, privacy, security and discount and offers. Through the four independent variables in our study we will check their impact on internet shopping and how much will be effect it. We will also check indirectly in our research the impact of other factors that can directly affect online shopping. And why in today's world in 21 st century most of the people don't prefer online shopping.

\section{Problem Statement}

Due to the existing lack of information on consumer attitude towards and adoption of online shopping in Bahawalpur, where the trend of online shopping is on the rise, this study was conducted using specific variables and dimensions.

\section{Research Gaps}

Online shopping is becoming trendy in Pakistan as well as in the rest of the world and ratio of online shopping in Pakistan was low in 2018 and in 2019 but in 2020 the ratio of online shopping was quite high. Many consumers rely on online shopping because of their busy schedule of their office and social life.

The basic gap for the study is to check the impact of four independent variables price, promotion, refund and culture. Least study has been carried upon these four variables. No such study has been carried out in the region of Bahawalpur City.

\section{Research Objectives}

RO1: How price factor is correlated with the consumer Attitude, when shopping online RO2: How Promotion factor is correlated with the consumer Attitude, when shopping online RO3: How Culture factor is correlated with the consumer Attitude, when shopping online RO4: How Refund factor is correlated with the consumer Attitude, when shopping online

\section{Literature Review}

The reason for writing literature review is to review discrimination purposes of variability of information including substantive discoveries and in addition will help shape hypothesis and methodology development. Other than that, writing audits otherwise called supporting sources, it just reporting the past examination and do not reveal any new or unique exploration data.

Researchers are curious to inspect online selling and buying of food and services by employing technologies such as web, electronic mail, electronic fund transfer and electronic data interchange. They have conducted many studies on those factors that link consumer to online shopping (Afizah, 2009). Investigated factors such as demographic profile, familiarity to internet, risk perception, convince, Attitude about online shopping, prices of product, product variety, promotion of products, product and 
service quality, product warranty, product and service cost, social norms, and consumer repurchase attitude due to refunding option in online shopping.

The world's total online industry is 1.5 trillion dollars and China is on the first number on this list. 7360 million people live in this world and total 2870 million people use internet, and 1200 million peoples are e shoppers. In this world total 160 billion dollars just invest on internet advertisement. This advertisement amount is 3x more than Pakistan's total budget. In only Europe 487 billion dollar invest on online shopping in a single year and with 450 billion dollars invest on ecommerce in North America. Top online sites in these developed countries are eBay, Amazon, Alibaba.com and Walmart. These four online shopping sites revenue is more then all remaining online sites. (Omar, 2016)

Pakistan total population is 200 million and total internet user almost 60 million in whole country. And total mobile connections is 130 million and total $3 \mathrm{G}$ and $4 \mathrm{G}$ connection are almost 40 million. Total ecommerce sale is 350 million. In an upcoming years these figures will be increased $70 \%$ to $75 \%$. Top online shopping sites in Pakistan are daraz.pk and Ali express. If you compare your ecommerce industry with a neighbouring country like India you can see rapid growth in last few years. The total Per Capita Spend on Ecommerce in India is 11.20\$ and it's 10 time more than Pakistan's. (Omar, 2016)

According to the examination, 90\% of online customers are planning to purchase more items online in which they feel positive experience of the clients. (Bhatt, 2014) Now a days shopping on internet is so difficult because even though internet consumers are faced with too many choices and facilities, most don't buy due to security and privacy issues. In this study we will find out the reasons, why most of the users still refuse to purchase their product. These type of security and privacy issues you can see only in undeveloped or developing nations because in developed nations consumers are fully satisfied with the product. (Bhatt, 2014) Broad companies like Amazon and eBay have introduced many feature like easy search, all products on a single site, and their consumers all fully satisfied with the security and privacy. And their consumers effectively and cleverly purchase product without visiting any store. After purchase online product, consumer feels the product they purchase on a less price then offering on offline stores and they save time and money also. (Bhatt, 2014)

Consumer perceived risk directly affects the buying decision of the consumers because the latest research suggests that risk perception plays a minor role in online shopping. In developing nations most of the consumers prefer to pay cash on delivery because they are afraid to pay in advance through banking channel. After paying through banking channel they feel exposed to the risk of cybercrimes. (Chen, 2005) Trust is directly proportional to consumer risk because trust reduces the risk perception of the buyer. If the online buyer feel lack of trust on any online site they can't purchase their product.

(Mydheen, 2016) The study shows that $95 \%$ of the college students use internet and $91 \%$ of the students purchase products online. In all of $91 \%$ students $1 / 4$ spent $500 \$$ annually on internet purchasing. They purchase tickets, banking services or entertainment products. Teenagers also buy motor cars and mortgages from the internet albeit in lesser figures. Ecommerce market sales increased every year in every country. In Pakistan growth rate of online sales increased every year, in upcoming years researchers feels that online sales market boost by $2 \mathrm{X}$. As per statistics India online shopping market is only 2.5 billion dollar in 2009 and they increased to 8.5 billion dollar in 2012. After a single year in 2013 market rise by 88 per cent and touch the figure of 16 billion dollars and this is the boosting point for Indian online shopping market. (Bhatt, 2014) In upcoming years researchers feels that these type of rising point for Pakistani online shopping industry.

While shopping online on internet we think about demographics such as gender, education, income and age because every consumer behaviour is different from each other. Online shopping mostly attracts elder and younger consumers because they are mostly attached with online shopping sites through internet. (Bhatt, 2014) 
Mega cities of Pakistan like Lahore, Karachi and Islamabad are the hub of IT industry. They are well educated and easily adopt latest technology. They don't have time to physically visit to offline stores, so most of the consumers prefer to shop online. They confirm their order online, save their traveling expenses and their time. All of the consumers they live in developing countries always prefer paid cash on delivery. (Pullokaran, 2018)

Ecommerce market's future is very bright because online shopping giving a best way to purchase product on a less price sitting in your home and purchase product with in your range. For example in India, Flipchart is offering best prices for their customers, consumers are fully satisfied and have a better experience with that. The whole idea of online shopping is changed due to his remarkable policies. (Kothari)

Online clients are more satisfied when marketers give importance to them and provide sales discount or provide relief in product prices. In this aggressive time period, online shopping advertisers focus on consumer loyalty to hold their current users and attract new consumers by offering every day new plans and offers for online buyers. Also studies showed that online shopping depended on different factors like product quality, broad variety in products, product offering on different prices, product packaging, payment security, banking channel security and so on.

Online shopping marketers focus on latest technology to attract their customers and add usage value in their mind through internet or social media or other sources. For a better marketing, marketers always make strategies they always meet with consumers demand. For making these type of strategies they study about the consumer behaviour or consumer attitude towards web shopping. Profession, location, age, income, gender and family status are the factors they directly affect the online buying decision. In some researches, researchers found that reduced prices, quick services and product variety are the factors which influence directly online shopping in all over the world. (Rajesh, 2018)

The use of internet increased day by day and they directly influence online shopping. Internet advertisers have created different promoting methodologies to convert their potential online clients into a regular consumers. Online shopping is effected by the consumers perception, five leading factors security and privacy, ease of use, perceived enjoyment, perceived usefulness and information about the online product are the factors they directly effects consumers perception and consumers perception is effected online shopping. (Rajesh, 2018) Online shopping is a way in which buyer and seller improve relationship with each other and reduce administrative cost or save time and money. The Internet and electronic business were the two generally critical improvements in 1990s. There is a remarkable growth in the number of consumers who purchase from the internet, as well as sales are also increased worldwide through online selling. (James, 2015)

\subsection{Online Shopping}

Internet is one of the several channels or medium for selling and buying goods and service online. Customer can use their credit card information on different websites and make online orders and the products are delivered to them instantly. This is called e-commerce or simply online shopping (Mazhar Et Al., 2012). Online shopping came into existence because of the internet and has revolutionized the past trade partners. It plays an important role in the circulation of merchandise, capital and the information (Quresh \& Sarwar, 2014).

Online shopping has become one of the important activities in the internet and information technology field. From the last few years, ample research has been carried out into adoption of information technology, testing a number of factors observed to be important for improved diffusion. Some information technology analysts characterized it as usefulness, as of use and source (Chiu, 2009) other focus on experience, attitude and emotions of user (Fiore \& kim, 2007, 2011) 


\subsection{Attitude}

An ongoing company of motivational, touching, perceptual, and cognitive techniques with admirers to a few factor of a person's perspective (( Consumer Behaviour, July 2000) In easy conditions, an attitude is the manner we imagine, feel and do something in the direction of a few feature of our surroundings such as an alternate store, television application, or invention. (consumer behaviour, 2000). Numerous researchers have done research in their effort to study the factors influencing client mind-set and belief to make e-trade purchases via online purchasing. Attitudes closer to online purchasing are described as a customer's high quality or bad emotions associated with undertaking the buying behaviour at the internet (Chiu et al. \& Schlosser, 2005, 2003). Buying traits and internet adoption symptoms were visible as the general digital commerce value in Pakistan Growing from many folds quite hastily in Pakistan. Pakistan, despite the fact that a past due entrant to the arena of e-trade, has currently recorded a huge upward push in on-line purchasing developments and different e-trade businesses. Such exponential boom traits during the last few years - with US\$30 million being spent on line purchases presently - depict an extraordinarily advantageous photo for the future and the dimensions of Pakistan's e-trade market is predicted to reach over US\$600 million by means of 2017 (Ahmed, 2015).

\subsection{Price}

Price is one of the crucial factors that affect when consumer buying online. (Sinha, 2001) If the price of the product is high then the consumer does not attract towards online buying. However, (al L. e., 1999) disagree that frequently online buyers are now not price-sensitive, the cause of those purchasers charge comparison among special e-business on every product became time-consuming and the fee distinction was very small. (Dholakia, 2003) Factor out that customers' preference of buying channels is tormented by the perceived prices related to a selected web site. Online clients evaluate expenses throughout the identical services or products supplied via specific websites on the way to make the only financial choice (al C. e., 2014). Because they cannot usually bear in mind the objective charge of an item, clients generally, tend to encode buy charges in a way this is significant to them.

While there is a sizeable range of web sites from which customers can choose and acquire charge records, they are possibly to make their decision on the idea of perceived fee. Perceived price affects purchaser purchase conduct with the aid of affecting the whole utility of the product presented ((Kim, 2012). (Gupta, 2009) Suggest that purchasers are likely to consider the referral prices supplied by means of different merchants.

H1- There is a positive relationship between the price and online shopping.

\subsection{Refund}

Online purchasers demanded that e-stores must provide unconditional refund coverage if the web costumer has been no longer satisfied with the product (Lee, 2002). E-stores need to have refund regulations to persuade online purchasers that they without difficulty go back merchandise and get refunds if they may be no longer glad or alternate merchandise without cost inside an affordable timeframe (Bishop, 1998).

H2- There is a positive relationship between the refund and online shopping.

\subsection{Promotion}

E-outlets would possibly use promotions with time limits to inspire customers to keep on internet site (Haig, 2001) . However, promotional activates for online services or products have been no longer a success for e-outlets due to the fact there were no longer powerful approaches to inform purchasers of promotional activities (Spiller, 1999).

H3- There is a positive \& significant relationship between the Promotion and online shopping.

\subsection{Culture}


Culture refers to the increasing deposit of information, skill, thinking, morals, attitudes, meanings, hierarchies, faith, theory of time, roles, spatial relations, concepts of the universe, and material objects and possessions acquired by a cluster of persons in the path of generation from side to side person and cluster determined (Karakowsky, (2001)). Culture is one of the key factors that have an effect on buying of the client. Culture factor contain set of values, belief and the ideology of specific community. Our subculture teaches us that as a purchase we need to make payments in contract or pay on time, and study guidelines and a few responsibilities when in search of information. Every culture split into subculture on the source of age, environmental surroundings, destiny, and gender. (Buzzle.com, n.d.)

H4- There is a positive \& significant relationship between the Culture and online shopping.

\section{Conceptual Framework}

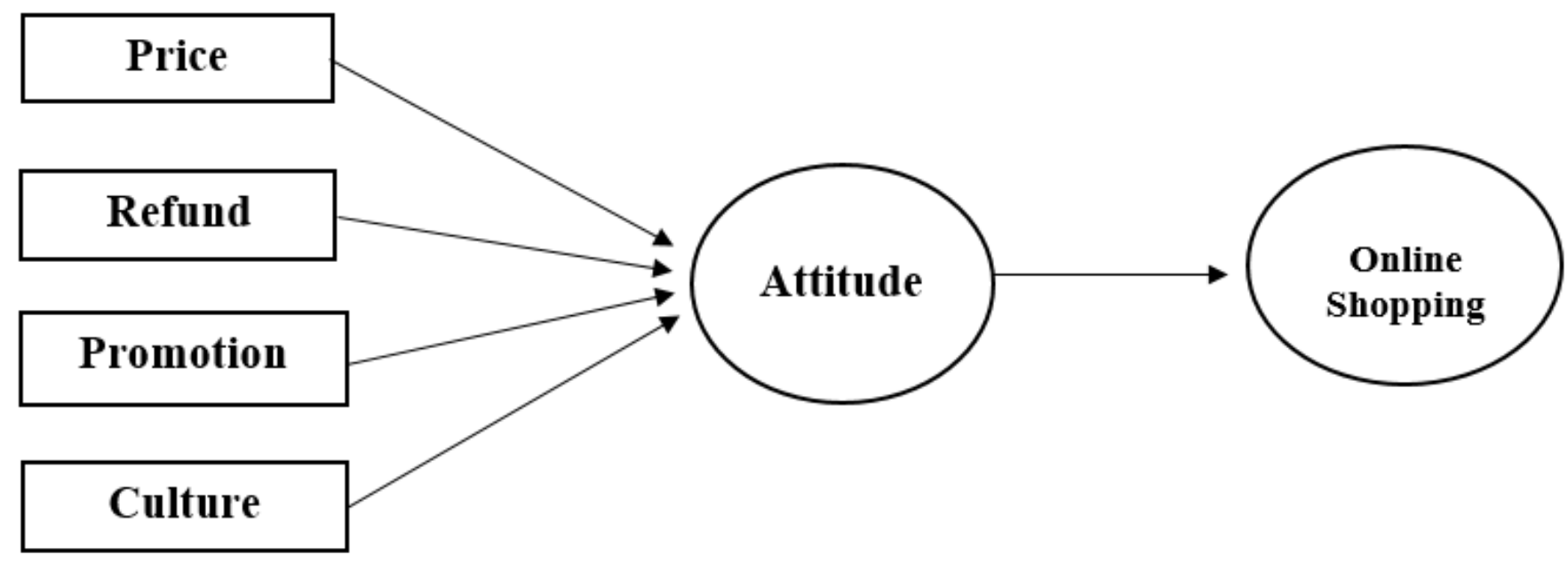

\section{Research Methodology}

This section discusses the research design, target population, sample size and research instrument and test used for empirical analysis in this study.

\subsection{Research Design}

A study's design is the blueprint that outlines every process from the speculation to the evaluation. This study's nature is explanatory. The outline of a few precise situations or some phenomenon is defined as explanatory research.

Explanatory research is examined planned to reveal the participant in a particular manner. More clearly placed, explanatory studies is all about recounting individuals who participate in the observing (https://study.com, n.d.)

The framework given above is for determining the consumer attitude towards online shopping. This model describes how consumer attitude are change due to the price, culture, promotions and refund.

\subsection{Target Population}

A population can be defined as including all people or items with the characteristic one wish to understand. Simple random sampling technique was used for population selection whereas simple random sampling techniques was used for population and data collection purpose. Simple random sampling is a sampling in which every person has an equal chance of being selected (Bryman\& Bell, 2005). Population refers to the totality of people, events, thing of interest or object (which may be individuals, households, organizations and countries etc.) that researcher wishes to investigate. The study-targeted people are who do online shopping and have had experience of online shopping. 


\subsection{Data Collection}

The research consists on primary data, collected from Bahawalpur. Efforts were made to collect data from both genders. Data was collected from people who buy online. Data was collected from 250 questionnaires. A questionnaire is pre-formulated written set of question to which respondents record their answer usually within rather closely defined alternatives.

\subsection{Sampling and Sample Size}

A subset of population selected to investigate the properties of the population because population are often extremely large or even infinite. It is usually impossible - for cost and practical reasons - to take measurement on every element of population. The study utilizes a simple random sampling. I have used the simple random sampling technique for data collection through questionnaire from those who are involved in online shopping. I have floated 270 questionnaires out of which 250 garnered responses. This method was adopted to speed up the researcher producer, by obtaining a large number of questionnaires efficiently and effectively. A statistical technique of drawing consultant data by using selecting human beings due to the convenience in their volunteering or choosing units due to their availability or clean access. (http://www.businessdictionary.com, n.d.)

\subsection{Research Instruments}

This study has collected data by method of self-administrated questionnaire and face-to-face interview. Questionnaire is made up of close-ended questions to find out the approximate accurate customer response.

\subsection{Data analysis Technique}

The next step was taken to enter, edit and analyse data to filter the measurement scales and guarantee their suitability by using SPSS (16.0) software using explanatory analysis techniques.

\subsection{Correlation}

The connection between two factors is estimated by relationship investigation. It expresses that the change in one variable is the reason the change in other variable. This test does not only measure the quality of connection between factors but also the course of relationship, whether it is negative or positive. Pearson correlation is the test which is run to measure the relation between variables to check that if there is any correlation between the variables. The result (called correlation coefficient) ranges from +1 to -1 , depicts the strength of relationship and sign with the result portrays the bearing of relationship either positive or negative separately. As expressed by Fidel and Tabachnick (2001), "Bivariate connection estimates the relationship between two

Cease less factors without building up directional causality".

\begin{tabular}{|l|l|l|l|l|l|l|}
\hline \multicolumn{2}{|c|}{ Correlations } \\
\hline \multicolumn{2}{|c|}{} & $\begin{array}{l}\text { Average } \\
\text { Online } \\
\text { Shopping }\end{array}$ & $\begin{array}{l}\text { Average } \\
\text { price }\end{array}$ & $\begin{array}{l}\text { Average } \\
\text { promotion }\end{array}$ & $\begin{array}{l}\text { Average } \\
\text { Refund }\end{array}$ & $\begin{array}{l}\text { Average } \\
\text { Culture }\end{array}$ \\
\hline $\begin{array}{l}\text { Average } \\
\text { Online } \\
\text { Shopping }\end{array}$ & Pearson Correlation & 1 & .005 & .301 & .379 & $.141^{*}$ \\
\cline { 2 - 8 } & Sig. (2-tailed) & $\mathrm{N}$ & .939 & .000 & .000 & .026 \\
\hline $\begin{array}{l}\text { Average } \\
\text { Price }\end{array}$ & Pearson Correlation & 249 & 249 & 249 & 249 & 249 \\
\cline { 2 - 8 } & Sig. (2-tailed) & .005 & 1 & $.861^{* *}$ & $.837^{* *}$ & $.715^{* *}$ \\
\cline { 2 - 8 } & $\mathrm{N}$ & .939 & & .000 & .000 & .000 \\
\hline $\begin{array}{l}\text { Average } \\
\text { promotion }\end{array}$ & Pearson Correlation & .301 & $.861^{* *}$ & 1 & $.964^{* *}$ & $.896^{* *}$ \\
\cline { 2 - 8 } & Sig. (2-tailed) & .000 & .000 & & .000 & .000 \\
\hline
\end{tabular}




\begin{tabular}{|l|l|l|l|l|l|l|}
\hline & $\mathrm{N}$ & 249 & 249 & 249 & 249 & 249 \\
\hline \multirow{2}{*}{$\begin{array}{l}\text { Average } \\
\text { Refund }\end{array}$} & Pearson Correlation & .379 & $.837 * *$ & $.964^{* *}$ & 1 & $.885^{* *}$ \\
\cline { 2 - 7 } & Sig. (2-tailed) & .000 & .000 & .000 & & .000 \\
\cline { 2 - 7 } & $\mathrm{N}$ & 249 & 249 & 249 & 249 & 249 \\
\hline \multirow{2}{*}{$\begin{array}{l}\text { Average } \\
\text { Culture }\end{array}$} & Pearson Correlation & $.141^{*}$ & $.715^{* *}$ & $.896^{* *}$ & $.885^{* *}$ & 1 \\
\cline { 2 - 7 } & Sig. (2-tailed) & .026 & .000 & .000 & .000 & 249 \\
\cline { 2 - 7 } & $\mathrm{N}$ & 249 & 249 & 249 & 249 & \\
\hline \multirow{2}{*}{$*$ Correlation is significant at the 0.05 level (2-tailed). } & & & \\
\hline \multirow{2}{*}{$* *$ Correlation is significant at the 0.01 level (2-tailed) }
\end{tabular}

\subsection{Interpretation}

Condensed aftereffects of coefficient relationship are given in the above table. A large portion of the qualities are noteworthy at 0.000 or under 0.05 . The factor between which there is no noteworthy relationship are price with a value 0.939 which is more than 0.05 . This means that price and online shopping have non-significant relationship hence the relationship between price and online shopping is non-significant. This means that when the price of a product in increased then the shopping is decreased.

The correlation between online shopping and promotion is significant with the value of 0.000 which is less than 0.05 hence the relationship between promotion and online shopping is significant. The Pearson correlation value is 0.301 which means that the correlation between promotion and online shopping is positively moderate. It means that when the promotion of a product is increased then the online sales are also increased.

The correlation between online shopping and Refund is significant with the value of 0.000 which is less than 0.05 hence the relationship between promotion and online shopping is significant. The Pearson correlation value is 0.379 which means that the correlation between refund and online shopping is positive. And it has a moderately weak relationship with each other. It means that when a customer buy a product and find any defect in that product and want to return it, and the company website offers the facility of refund then the online sales are also be increased. Because the customers don't have to pay for the defective product.

The correlation between online shopping and culture is significant with the value of 0.026 which is less than 0.05 hence the relationship between promotion and online shopping is significant. The Pearson correlation value is 0.141 which means that the correlation between culture and online shopping is positively weak. It means that when the culture of the customer is changed to the higher level than online sales are also increased. Because usually it is seen that the people from villages of background areas don't have the facility of online shopping.

\section{Regression Analysis}

\begin{tabular}{|c|c|c|c|c|}
\hline \multicolumn{5}{|c|}{ Model Summary } \\
\hline Model & $\mathrm{R}$ & R Square & Adjusted R Square & $\begin{array}{l}\text { Std. Error of the } \\
\text { Estimate }\end{array}$ \\
\hline 1 & $.369 a$ & .136 & .122 & .60246 \\
\hline
\end{tabular}

\begin{tabular}{|l|l|l|l|l|}
\hline Coefficients & \multicolumn{3}{|l|}{ Sig. } \\
\cline { 1 - 3 } & $\begin{array}{l}\text { Unstandardized } \\
\text { Coefficients }\end{array}$ & $\begin{array}{l}\text { Standardized } \\
\text { Coefficients }\end{array}$ & t & Sig. \\
\cline { 2 - 4 } & B & Std. Error & Beta & \\
\hline
\end{tabular}




\begin{tabular}{|l|l|l|l|l|l|l|}
\hline 1 & $\begin{array}{l}\text { (Constant } \\
\text { ) }\end{array}$ & 2.435 & .306 & & 7.959 & .000 \\
\cline { 2 - 7 } & $\begin{array}{l}\text { Average } \\
\text { price }\end{array}$ & .236 & .139 & .207 & 1.703 & .090 \\
\cline { 2 - 6 } & $\begin{array}{l}\text { Average } \\
\text { promotio } \\
\text { n }\end{array}$ & -1.211 & .254 & -1.273 & -4.777 & .000 \\
\cline { 2 - 7 } $\begin{array}{l}\text { Average } \\
\text { Refund }\end{array}$ & .090 & .039 & .129 & 2.327 & .021 \\
\hline $\begin{array}{l}\text { Average } \\
\text { Culture }\end{array}$ & .860 & .158 & .768 & 5.440 & .000 \\
\hline a. Dependent Variable: Average Online Shopping & & \\
\hline
\end{tabular}

\section{Interpretation}

The 1 st hypothesis that the significance value is .090 which is greater than 0.05 . As we know that the significance value should be less than 0.05 . If this situation occurs, then the hypothesis is accepted. But in our situation the significance value is greater. Hence it is not significant and our hypothesis is rejected which means that price don't have the positive relationship with the online shopping. It means that when the price of products on online websites is increased then the sales on those sites is decreased.

The 2nd hypothesis that the significance value is 0.000 which is less than 0.05 . So our hypothesis is accepted and it is said that if the promotions are increased then the sales on online websites is also increased. Similar studies discuss about the promotion of the products, like in Invalid source specified. It is stated that the promotions and the online shopping are significant.

The 3rd hypothesis that the significance value is 0.021 which is less than 0.05 . So our hypothesis is accepted and it is said that if the refund policy is good then the sales will be also good on online websites.

The 4th hypothesis that the significance value is 0.000 which is less than 0.05 . So our hypothesis is accepted and it is said that if the culture is changed positively or negatively then the sales are also effected respectively.

\section{Conclusion}

Internet is a useful medium for buying goods and services online. Customer can be made aware of goods and services through promotions, place their orders and those products are delivered in a timely manner. This is called 'E-Commerce' or simply online shopping. Companies can develop consumer attitude through promotion, refund and pricing strategies.

There are more than 10 million users of internet in Pakistan and this number is growing. A lot of internet users focus on promotion that is on social media from the company. The social networking websites also provide platform to attract customers from different pricing strategies and promotion and money back guarantee on different product. Culture plays vital role while shopping online. Price, promotion, refund and culture directly affect consumer's attitude and change the buying behaviour of consumer.

This research addressed the gap in the literature on the relationship of price, promotion, refund and culture. As the primary aim of the study was to find out the factor-affecting attitude of consumer towards online shopping it started with an extensive review of the literature based on which hypothesis construct and relationships under examination were set out. Through fieldwork appropriate data was collected. The study used simple random sampling technique. It employed a survey strategy that used structured questionnaire to collect data. Finally statistical techniques, reliability of scale, regression analysis, and frequency test employed these were used in a confirmatory manner to seek answers establishing causality. 
Hence, all factor chosen supposed to affecting the consumer attitude towards online shopping. As per analysis, there is no multi collinearity in indicators.

According to my findings, Online Shopping is getting popularity in the young generation such as students and professionals. Students usually prefers to buy goods from the original source and they mostly prefer online shopping.

\section{Research Limitations}

The scope of the present research is limited. The first limitation is the population selected was only from Bahawalpur, Pakistan and that does not cover the population of whole country especially from the big cities where online shopping is all the rage. The results will definitely be varied if the research is conducted in the whole country. Time constraint along with the financial constraint is the second limitation of this research.

The main hurdle faced by the researcher is the inaccessibility of articles as well as books from library. Internet is not included in the review due to Refunding factor and hence the inaccessibility of the resources that is the third limitation of this study.

Another major limitation of this study is the cooperation of participants and honesty in answering the questions. In spite of these limitations, there's hope that this research will be of considerable worth to the research stream of consumer attitude towards online shopping.

\section{Future Research}

This research has been done by taking four independent variable price, promotion refund and culture on dependent variable online shopping. There are many other ways to conduct the research like by taking into account things like website development, time saving and trust to check the impact on consumer attitude towards online shopping. Furthermore, this research can be conducted by taking price, promotion refund and culture independent variable, and also check the impact of attitude on online shopping with online shopping as the dependent variable.

This research has been done under certain limitations that can be removed in future research to get the more concrete results. Next time the population of whole Pakistan with more sample size can give results that are more valid. More time and sufficient financial resources are one of the major sources that can help to get better results. The access of wide range of books, articles and research papers are the basis of making strong background and literature review of the research.

\section{References}

Abrar, K. (2017). Impact of Perceived Risk on Online Impulse Buying Tendency: an. Journal of Accounting.

Ahmed, J. (2015). The encouraging future of e-commerece in Pakistan. Tech in Asia.

Bhatt, P. A. (2014). "Consumer Attitude towards Online Shopping in Selected Regions of Gujarat. Journal of Marketing Management, 28.

Chen, G. S. (2005). WEB-BASED SHOPPING: CONSUMERS' ATTITUDES TOWARDS ONLINE. Journal of Electronic Commerce Research, 16.

Folarin, T. O. (2016). INFLUENCE OF CUSTOMERS' PERCEIVED RISK ON ONLINE SHOPPING. International Journal of Information System and Engineering.

James, A. T. (2015). Consumers' attitude towards online shopping: Factors influencing employees of crazy domains to shop online. Journal of Management and Marketing Research, 11.

Kooli, D. K. (n.d.). Determinants of online trust and their impact on online purchase.

Kothari, P. P. (n.d.). A Study on Customers Attitude towards Online Shopping in India. international journal of advanced research, 10.

Mydheen, D. N. (2016). A STUDY ON ATTITUDE OF STUDENTS TOWRADS ONLINE 
PURCHASING. EPRA internation of journal economics and business review, 6 .

Omar, S. (2016). Cracking E-commerce 2.0: Whitepaper on taking 500,000 merchants online in Pakistan. Planet $\mathrm{N}$ group, 25.

Pullokaran, L. J. (2018). A Study on Consumer's attitude towards online shopping of smartphone . International Journal of Scientific and Research Publications, 10.

Rajesh, R. (2018). EVALUATING THE FACTORS INFLUENCING ONLINE SHOPPING AND ITS CONSUMER SATISFACTION IN PUNE. International Journal of Social Sciences , 23.

Shamout, M. D. (2016). The Impact of Promotional Tools on Consumer Buying Behavior in Retail Market. International Journal of Business and Social Science .

Shi, F. a. (2016). Perceived Risk of Online Shopping.

Sims, J. (2012). Perceived Risk of Online Shopping: Differences. UK Academy for Information Systems. Ahmed, J. (2015). The encouraging future of e-commerece in Pakistan. Tech in Asia.

Chiu et al., 2., \& Schlosser, 2. (2005, 2003). trend of e-commerece.

consumer behaviour. (2000). IuP Publication. 
